\title{
Comparison of the effect of light alcohol consumption on Japanese men with and without fatty liver
}

\author{
TASUKU HARA $^{1,2}$, YUYA SEKO ${ }^{2}$, NAOTO IWAI ${ }^{1}$, YUTAKA INADA ${ }^{1}$, TOSHIFUMI TSUII ${ }^{1}$, \\ TAKASHI OKUDA ${ }^{1}$, TOSHIYUKI KOMAKI ${ }^{1}$, YOSHITO ITOH ${ }^{2}$ and KEIZO KAGAWA ${ }^{1}$ \\ ${ }^{1}$ Department of Gastroenterology and Hepatology, Fukuchiyama City Hospital, Fukuchiyama City, Kyoto 620-8505; \\ ${ }^{2}$ Department of Gastroenterology and Hepatology, Kyoto Prefectural University of Medicine, \\ Kamigyou-ku, Kyoto 602-8566, Japan
}

Received July 29, 2019; Accepted August 23, 2019

DOI: $10.3892 / b r .2019 .1242$

\begin{abstract}
Light and moderate drinking is associated with lower risk of metabolic syndrome (Mets)-related diseases in the general population. Non-alcoholic fatty liver disease (NAFLD) is considered to be a phenotype of Mets in the liver. Although there have been some reports of the association between NAFLD and light alcohol consumption (LAC), the association between Mets-related diseases and LAC in the subjects with and without fatty liver is unclear. Therefore, this study aimed to determine the influence of LAC on Mets-related diseases in individuals with and those without fatty liver. This study included 1,190 men who underwent regular health check-ups and consumed $<20 \mathrm{~g} /$ day of alcohol. The subjects were divided into two groups, the non-fatty liver group and fatty liver group, and investigated the association between Mets-related diseases and LAC. Fatty liver was diagnosed by abdominal ultrasound. The effect of LAC was different between the non-fatty liver and fatty liver groups. In the non-fatty liver group, the odds ratio (OR) for hypertension was 1.73 (1.04-2.88;2 $\mathrm{P}=0.035)$. In the fatty liver group, the $\mathrm{OR}$ for each Mets-related diseases were as follows: Dyslipidemia, 0.64 (0.44-0.95, $\mathrm{P}=0.028)$; impaired glucose tolerance 0.57 (0.37-0.88; $\mathrm{P}=0.012)$; chronic kidney disease, 0.58 (0.36-0.94; $\mathrm{P}=0.029)$; and Mets by Japanese criteria, $0.63(0.44-0.92 ; \mathrm{P}=0.016)$. The influence of LAC on Mets-related diseases differs based on the presence of fatty liver. In individuals without fatty liver, light drinking is an independent risk factor for hypertension.
\end{abstract}

\section{Introduction}

The prevalence of metabolic syndrome (Mets), which is defined as obesity with hypertension or glucose intolerance, has been

Correspondence to: Dr Tasuku Hara, Department of Gastroenterology and Hepatology, Fukuchiyama City Hospital, 231 Atsunaka-chou, Fukuchiyama City, Kyoto 620-8505, Japan

E-mail: t-hara@koto.kpu-m.ac.jp

Key words: light alcohol consumption, fatty liver, metabolic syndrome, hypertension, regular health check-up increasing worldwide and varies from $12-41 \%$ (1). Several studies demonstrated that moderate alcohol consumption reduces the risk of Mets-related diseases and mortality (2-8). Light or moderate alcohol consumption is reported to enhance insulin sensitivity, increase high-density lipoprotein cholesterol (HDL-C) and reduce the risk of type 2 diabetes mellitus (9). Moreover, non-alcoholic fatty liver disease (NAFLD) is considered a phenotype of Mets in the liver (10-12). According to previous studies in Japan, the prevalence of NAFLD in the general population ranges from $24.6-29.7 \%(13,14)$ and light or moderate alcohol consumption is negatively associated with fatty liver (15-19). Previously, chronic kidney disease (CKD) has been considered a renal phenotype of Mets (20). Previous studies reported that light or moderate alcohol consumption reduced the risk of CKD $(21,22)$. Elevated serum uric acid has been proposed as a risk factor for not only CKD (23) but also diabetes (24) and hypertension (25). While alcohol consumption has been recognized as an important risk factor for gout and hyperuricemia, moderate alcohol consumption does not increase the risk of hyperuricemia $(26,27)$. However, certain studies reported that even light alcohol consumption (LAC) could increase blood pressure in Japanese men (28-30).

Recently, liver dysfunction and hypercholesterolemia have been reported as the most common abnormal findings associated with Mets among individuals who underwent a regular health check-up in Japan. The main reason for the increase in liver dysfunction is associated with the increasing incidence of NAFLD (31). Although there have been some reports on the effect of LAC on Mets-related diseases in individuals with NAFLD, the association between LAC and each Mets-related disease among those with or without fatty liver is unclear. Therefore, this study investigated the effect of LAC on Mets-related diseases, such as obesity, dyslipidemia, impaired glucose tolerance (IGT), hyperuricemia and CKD, in individuals with and without fatty liver.

\section{Patients and methods}

Subjects. In this cross-sectional study, 2,096 men who underwent regular health check-up, including physical and physiological examinations, abdominal ultrasound, and blood screening examination, between January 2017 and 
December 2017 at Fukuchiyama City Hospital (Fukuchiyama City, Japan) were enrolled. Subjects were included if they fulfilled the following criteria: Absence of markers of hepatitis B surface antigen and hepatitis C antibody, alcohol consumption $\geq 20 \mathrm{~g} / \mathrm{day}$, and chronic liver diseases, including autoimmune hepatitis, primary biliary cholangitis, and drug-induced liver disease. Patients judged to be inappropriate for this study were excluded ( $n=906)$. A total of 1,190 eligible subjects were analyzed. Patient characteristics are shown in Table I. All patients provided written informed consent prior to participation and the study was conducted in accordance with the Declaration of Helsinki and was approved by the institutional review board of Fukuchiyama City Hospital.

Physical examination and serum biochemistry. The subjects were divided into two groups: Fatty liver group and non-fatty liver group. Body weight and height were obtained for both groups, and body mass index (BMI) was calculated. Waist circumference (WC) was measured at the level of the umbilicus according to the definition in the Japanese Committee for the Diagnostic Criteria of Metabolic Syndrome (32). Venous blood samples $(10 \mathrm{ml})$ were obtained from all subjects following a 12-h overnight fast. Aspartate aminotransferase, alanine aminotransferase, $\gamma$-glutamyl transpeptidase (GGT), total cholesterol, HDL-C, triglycerides (TG), low-density lipoprotein cholesterol (LDL-C), uric acid (UA), fasting plasma glucose (FPG), hemoglobin A1c (HbAlc; National Glycohemoglobin Standardization Program) and estimated glomerular filtration rate (eGFR) were measured using standard clinical chemistry laboratory techniques.

Assessment of fatty liver. All the subjects received an abdominal ultrasound to assess fatty liver. Experienced technicians performed real-time ultrasonography to detect vascular blurring, deep attenuation and increased liver echotexture in comparison to the kidneys (liver-kidney contrast) to assess fatty infiltration (33). Each certificated gastroenterologist independently reviewed the images and judged that the presence of one or more findings was indicative of a fatty liver.

Evaluation of alcohol consumption. Lifestyle-related information, such as medical history, smoking status and alcohol consumption, was obtained using a common standardized self-response questionnaire. The amount of alcohol consumption per day was calculated in grams using the representative percentage of alcohol by volume of each type of alcohol beverage. Subjects were classified into two groups according to drinking information: Non-drinkers and light drinkers; the latter is defined as those who consumed $>0$ to $<20 \mathrm{~g}$ of alcohol per day.

Variables. Obesity was defined as BMI $\geq 25 \mathrm{~kg} / \mathrm{m}^{2}$, which is the commonly used definition of obesity in the Japanese population (34). Hypertension was defined as systolic blood pressure (SBP) $\geq 140 \mathrm{mmHg}$, diastolic blood pressure (DBP) $\geq 90 \mathrm{mmHg}$, or the use of medications for hypertension. Dyslipidemia was defined as TG $\geq 150 \mathrm{mg} / \mathrm{dl}$, HDL-C $<40 \mathrm{mg} / \mathrm{dl}$ and LDL-C $\geq 140 \mathrm{mg} / \mathrm{dl}$ or the use of medications for dyslipidemia. IGT was defined as FPG $\geq 110 \mathrm{mg} / \mathrm{dl}$ or the use of medications for diabetes mellitus. Hyperuricemia was defined as UA $>7.0 \mathrm{mg} / \mathrm{dl}$ or the use of medications for hyperuricemia. CKD was defined as eGFR $<60 \mathrm{ml} / \mathrm{min} / 1.73 \mathrm{~m}^{2}$ and/or overt proteinuria (35). According to the Japanese criteria, Mets is defined as $\mathrm{WC} \geq 85 \mathrm{~cm}$ and the presence of two or more of the following risk factors: $\mathrm{SBP} \geq 130 \mathrm{mmHg}$ or DBP $\geq 85 \mathrm{mmHg}$; reduced HDL-C (HDL-C $<40 \mathrm{mg} / \mathrm{dl}$ ) and/or increased TG $(\mathrm{TG} \geq 150 \mathrm{mg} / \mathrm{dl})$; and $\mathrm{FPG} \geq 110 \mathrm{mg} / \mathrm{dl}$.

Statistical analysis. Baseline data were expressed as median with interquartile range and subject number (\%) for categorical variables. P-values were calculated using a Mann-Whitney U test for continuous variables and Fisher's exact probability test or the Chi square test for categorical variables. Factors with a significant influence on the prevalence of hypertension in the non-fatty liver group were determined by univariate analysis. Age, obesity, dyslipidemia, IGT, hyperuricemia, CKD, smoking and LAC were subsequently subjected to multivariable logistic regression analyses. $\mathrm{P}<0.05$ was considered to indicate a statistically significant difference. IBM SPSS version 16.0 for Windows (SPSS, Inc.) was used in the statistical analyses.

\section{Results}

Clinical characteristics of non-drinkers and light drinkers. The protocol followed for participant selection and enrollment is shown in Fig. 1. Of the 2,096 participants, 906 were excluded. Of the 1,190 participants included in the analysis, 505 (42.4\%) were non-drinkers and $685(57.6 \%)$ were light drinkers. Table I shows the comparison of the clinical characteristics between non-drinkers and light drinkers. No significant difference was noted between non-drinkers and light drinkers in terms of age and BMI. TG, LDL, HbAlc and the prevalence of proteinuria were significantly decreased in light drinkers compared with in non-drinkers $(\mathrm{P}<0.01)$. DBP, HDL, GGT, and Fib-4 index were significantly increased in light drinkers compared with in non-drinkers $(\mathrm{P}<0.05)$. No significant difference was observed between non-drinkers and light drinkers in the prevalence of hypertension and hyperuricemia. The prevalence of obesity, dyslipidemia, IGT, fatty liver, CKD and Mets, according to the Japanese criteria, was significantly decreased in light drinkers compared with in non-drinkers $(\mathrm{P}<0.05)$; in fact, this prevalence was lowest in light drinkers among the 4 groups of participants (non-drinkers; light drinkers, alcohol use/day $<20 \mathrm{~g}$; moderate drinkers, alcohol use/day 20-59 g; heavy drinkers, alcohol use/day $\geq 60 \mathrm{~g}$; Table SI). Among the lifestyle parameters, regular exercise habit was significantly more prevalent in light drinkers than in non-drinkers $(\mathrm{P}<0.05)$, but no significant difference was noted between non-drinkers and light drinkers in terms of current smoking.

Treatment for each Mets-related diseases in non-drinkers and light drinkers. A comparison of the treatment for each Mets-related disease between non-drinkers and light drinkers is shown in Table II. No significant difference in the treatment for hypertension was observed between non-drinkers and light drinkers. DBP in those without treatment for hypertension was significantly increased in light drinkers compared with in non-drinkers $(\mathrm{P}<0.01)$. No significant difference in the treatment for dyslipidemia was noted between non-drinkers and 
Table I. Comparison of clinical characteristics between non-drinkers and light drinkers.

\begin{tabular}{|c|c|c|c|}
\hline Characteristics & Non-drinker $(n=505)$ & Light drinker $(\mathrm{n}=685)$ & P-value \\
\hline Age (years) & $56(28-83)$ & $56(24-78)$ & 0.920 \\
\hline BMI $\left(\mathrm{kg} / \mathrm{m}^{2}\right)$ & $23.6(15.2-52.9)$ & $23.3(16.0-41.4)$ & 0.150 \\
\hline $\mathrm{WC}(\mathrm{cm})$ & $85.5(61.0-143.0)$ & $85.0(63.0-127.0)$ & 0.080 \\
\hline Obesity & $174(34.4)$ & $195(28.3)$ & 0.020 \\
\hline $\mathrm{SBP}(\mathrm{mmHg})$ & $126(93-196)$ & $128(94-190)$ & 0.212 \\
\hline $\mathrm{DBP}(\mathrm{mmHg})$ & $79(48-122)$ & $81(54-112)$ & 0.028 \\
\hline Hypertension & $200(39.6)$ & $298(43.3)$ & 0.194 \\
\hline T-CHO (mg/dl) & $197(86-330)$ & $195(106-312)$ & 0.769 \\
\hline TG (mg/dl) & $104(18-772)$ & $93(28-648)$ & 0.009 \\
\hline HDL (mg/dl) & $50(26-93)$ & $54(27-100)$ & $<0.001$ \\
\hline LDL (mg/dl) & $123(33-228)$ & $119(47-229)$ & 0.007 \\
\hline Dyslipidemia & $296(58.6)$ & $329(47.8)$ & $<0.001$ \\
\hline FPG (mg/dl) & $98(74-284)$ & $98(76-291)$ & 0.149 \\
\hline HbA1c (NGSP) (\%) & $5.9(4.6-12.0)$ & $5.8(4.9-11.1)$ & 0.016 \\
\hline IGT & $119(23.5)$ & $117(17.0)$ & 0.006 \\
\hline $\mathrm{UA}(\mathrm{mg} / \mathrm{dl})$ & $5.8(0.9-11.1)$ & $6.0(0.9-9.6)$ & 0.076 \\
\hline Hyperuricemia & $106(20.9)$ & 148 (21.6) & 0.798 \\
\hline AST (IU/l) & $21(12-64)$ & $22(12-124)$ & 0.094 \\
\hline ALT (IU/l) & $22(6-108)$ & $21(9-148)$ & 0.314 \\
\hline GGT (IU/1) & $26(9-202)$ & $30(9-737)$ & 0.001 \\
\hline Fib-4 index & $1.07(0.29-3.96)$ & $1.16(0.35-3.86)$ & 0.027 \\
\hline Fatty liver & $269(53.7)$ & $292(42.8)$ & $<0.001$ \\
\hline eGFR $\left(\mathrm{ml} / \mathrm{min} / 1.73 \mathrm{~m}^{2}\right)$ & $75.7(12.2-151.5)$ & $75.8(40.9-136.1)$ & 0.644 \\
\hline Proteinuria & $41(8.1)$ & $32(4.6)$ & 0.014 \\
\hline CKD & $91(18.0)$ & $89(12.9)$ & 0.017 \\
\hline Mets by Japanese criteria & $145(28.7)$ & $144(20.9)$ & 0.002 \\
\hline Regular exercises & $109(21.5)$ & $192(28.0)$ & 0.011 \\
\hline Current smoking & 99 (19.6) & $124(18.1)$ & 0.512 \\
\hline
\end{tabular}

Results are presented as n (\%) for qualitative data or as median (range) for quantitative data. Light drinker, 0-19 g alcohol/day. AST, aspartate aminotransferase; ALT, alanine aminotransferase; BMI, body mass index; CKD, chronic kidney disease; DBP, diastolic blood pressure; eGFR, estimated glomerular filtration rate; FPG, fasting plasma glucose; GGT, $\gamma$-glutamyl transpeptidase; HbAlc, hemoglobin A1c; HDL, high-density lipoprotein; IGT, impaired glucose tolerance; LDL, low-density lipoprotein; Mets, metabolic syndrome; NGSP, National Glycohemoglobin Standardization Program; SBP, systolic blood pressure; T-CHO, total cholesterol; TG, triglycerides; UA, uric acid; WC, waist circumference.

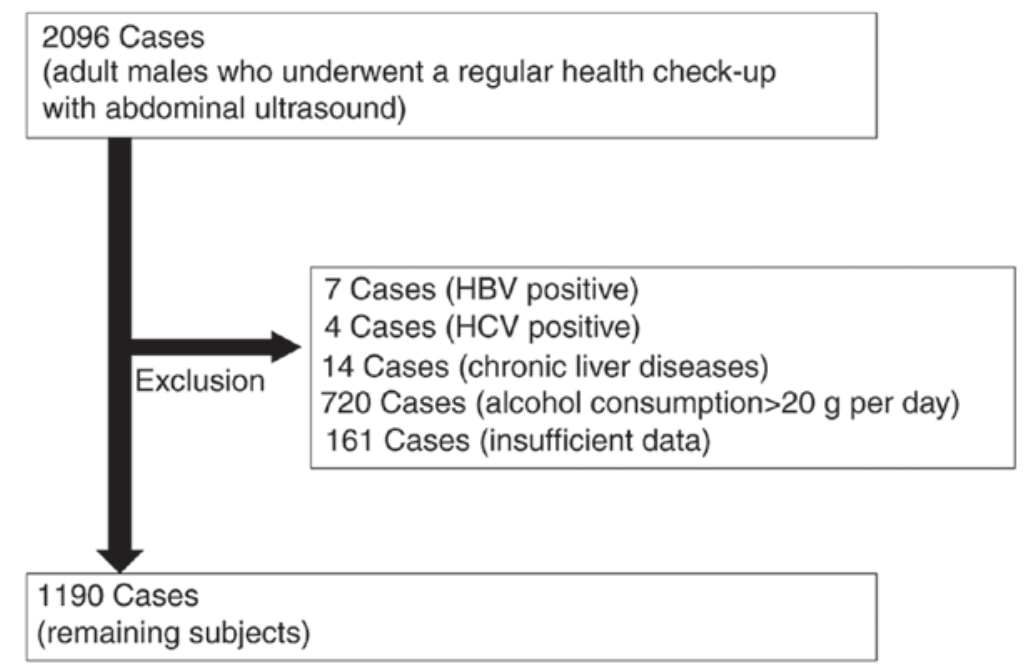

Figure 1. Flow diagram of selection of subjects for this study. HBV, hepatitis B virus; HCV, hepatitis C virus. 
Table II. Comparison between non- and light drinkers receiving treatment for Mets-associated diseases.

\begin{tabular}{lccc}
\hline A, Hypertension & & & \\
\hline Characteristics & Non-drinker $(\mathrm{n}=505)$ & Light drinker $(\mathrm{n}=685)$ & P-value \\
\hline Treatment & $119(23.6)$ & $159(23.2)$ & 0.887 \\
SBP $(\mathrm{mmHg})$ & $132(101-179)$ & $132(94-170)$ & 0.383 \\
DBP $(\mathrm{mmHg})$ & $83(54-111)$ & $53(54-109)$ & 0.404 \\
Treatment (-) & $386(76.4)$ & $126(94-190)$ & 0.068 \\
SBP $(\mathrm{mmHg})$ & $123(96-196)$ & $81(56-112)$ & 0.003 \\
DBP $(\mathrm{mmHg})$ & $78(48-122)$ & & \\
\hline
\end{tabular}

B, Dyslipidemia

\begin{tabular}{lccr}
\hline Characteristics & Non-drinker $(\mathrm{n}=505)$ & Light drinker $(\mathrm{n}=685)$ & P-value \\
\hline Treatment $(+)$ & $101(20.0)$ & $108(15.7)$ & 0.058 \\
T-CHO (mg/dl) & $185(114-330)$ & $181(128-293)$ & 0.894 \\
TG $(\mathrm{mg} / \mathrm{dl})$ & $113(42-772)$ & $100(42-304)$ & 0.310 \\
HDL $(\mathrm{mg} / \mathrm{dl})$ & $49(26-77)$ & $54(31-93)$ & 0.004 \\
LDL $(\mathrm{mg} / \mathrm{dl})$ & $110(46-228)$ & $105(61-203)$ & 0.105 \\
Treatment $(-)$ & $404(80.0)$ & $577(74.3)$ & 0.484 \\
T-CHO (mg/dl) & $202(86-300)$ & $91(28-648)$ & 0.028 \\
TG $(\mathrm{mg} / \mathrm{dl})$ & $101(18-687)$ & $54(27-100)$ & $<0.001$ \\
HDL $(\mathrm{mg} / \mathrm{dl})$ & $51(27-93)$ & $121(47-229)$ & 0.006 \\
LDL $(\mathrm{mg} / \mathrm{dl})$ & $126(33-202)$ & & \\
\hline
\end{tabular}

C, IGT

\begin{tabular}{lccr}
\hline Characteristics & Non-drinker $(\mathrm{n}=505)$ & Light drinker $(\mathrm{n}=685)$ & $\mathrm{P}$-value \\
\hline Treatment (+) & $44(8.7)$ & $38(5.5)$ & 0.033 \\
FPG (mg/dl) & $130(83-84)$ & $134(87-220)$ & 0.649 \\
HbA1c (NGSP) (\%) & $7.0(5.0-12.0)$ & $6.8(6.1-10.8)$ & 0.666 \\
Treatment (-), n (\%) & $461(91.3)$ & $647(94.5)$ & $97(76-291)$ \\
FPG (mg/dl) & $98(74-156)$ & $5.7(4.9-11.1)$ & 0.360 \\
HbA1c (NGSP) (\%) & $5.8(4.6-8.4)$ & & 0.051 \\
\hline
\end{tabular}

D, Hyperuricemia

\begin{tabular}{lccr}
\hline Characteristics & Non-drinker $(\mathrm{n}=505)$ & Light drinker $(\mathrm{n}=685)$ & P-value \\
\hline Treatment $(+)$ & $30(5.9)$ & $52(7.6)$ & 0.229 \\
$\mathrm{UA}(\mathrm{mg} / \mathrm{dl})$ & $6.2(4.3-7.9)$ & $6.5(3.6-8.7)$ & 0.296 \\
Treatment $(-), \mathrm{n}(\%)$ & $475(94.1)$ & $632(92.4)$ & 0.148 \\
UA (mg/dl) & $5.8(0.9-11.1)$ & $6.0(0.6-9.6)$ & \\
\hline
\end{tabular}

Results are presented as n (\%) for qualitative data or as median (range) for quantitative data. Light drinker, 0-19 g alcohol/day. DBP, diastolic blood pressure; FPG, fasting plasma glucose; HbA1c, hemoglobin A1c; HDL, high-density lipoprotein; IGT, impaired glucose tolerance; LDL, low-density lipoprotein; Mets, metabolic syndrome; NGSP, National Glycohemoglobin Standardization Program; SBP, systolic blood pressure; T-CHO, total cholesterol; TG, triglycerides; UA, uric acid.

light drinkers. Regardless of treatment for dyslipidemia, HDL was significantly increased in light drinkers compared with in non-drinkers $(\mathrm{P}<0.001)$. TG and HDL levels in those without treatment for dyslipidemia were significantly decreased in light drinkers compared with those in non-drinkers. The number of subjects receiving treatment for IGT was significantly 
decreased among light drinkers compared with among non-drinkers $(\mathrm{P}<0.05)$. No significant difference was found in the treatment for hyperuricemia between non-drinkers and light drinkers.

Prevalence of Mets-related diseases and risk factors between non-drinkers and light drinkers. A comparison of the prevalence of each risk factor for Mets-related diseases between non-drinkers and light drinkers in the non-fatty liver and fatty liver groups are shown in Table III. In the non-fatty liver group, no significant difference was found in age and BMI between non-drinkers and light drinkers. The prevalence of hypertension was significantly increased in light drinkers compared with in non-drinkers $(\mathrm{P}<0.05$; Table III). In the fatty liver group, no significant difference was observed in age and BMI between non-drinkers and light drinkers. The prevalence of dyslipidemia, IGT and Mets by the Japanese criteria was significantly decreased in light drinkers than in non-drinkers $(\mathrm{P}<0.05$; Table III).

Odds ratio for each Mets-related diseases comparing light drinkers to non-drinkers. The odds ratio [OR; 95\% confidence interval (CI), P-value] for each Mets-related disease in light drinkers and non-drinkers is shown in Fig. 2. In the non-fatty liver group, the OR for hypertension among light drinkers was 1.73 (1.04-2.88, $\mathrm{P}=0.035)$. In the fatty liver group, the OR for each Mets-related disease among light drinkers were as follows: Dyslipidemia, 0.64 (0.44-0.95, P=0.028); IGT, 0.57 (0.37-0.88, $\mathrm{P}=0.012)$; CKD, $0.58(0.36-0.94, \mathrm{P}=0.029)$ and Mets by the Japanese criteria, $0.63(0.44-0.92, \mathrm{P}=0.016)$.

\section{Discussion}

In this cross-sectional study, the results indicated that the effect of LAC was different between individuals with and those without fatty liver. In the non-fatty liver group, the prevalence of hypertension in light drinkers was $35.3 \%$, which was increased compared with in non-drinkers (26.6\%). In the fatty liver group, the prevalence of dyslipidemia, IGT, CKD and Mets by the Japanese criteria was lower in light drinkers than that in non-drinkers.

Fatty liver among non-drinkers and light drinkers was diagnosed as NAFLD, which is considered a phenotype of Mets in the liver (10-12). Previous studies reported that light or moderate alcohol consumption is negatively associated with fatty liver (15-19). The mechanism of inverse association of alcohol consumption with fatty liver has been previously elucidated. Moderate alcohol consumption has been shown to reduce fasting serum insulin and TG levels and is associated with a lower incidence of diabetes, all of which are important risk factors for the development of NAFLD $(2,36)$. In addition, certain studies revealed that the level of adiponectin, which is a hormone involved in lipid and glucose homeostasis and is reduced in patients with NAFLD, is upregulated in people who consume alcohol (37-39). Antioxidant agents in alcoholic beverages, mostly in wine (15), may also exert a protective effect in NAFLD. In this study, the serum levels of TG, LDL and HbAlc were lower, and the prevalence of IGT and fatty liver was decreased in light drinkers compared with in non-drinkers.
The relationship between alcohol consumption and all-cause mortality has been reported to have J- or U-shaped curve (8). This effect is thought to be mainly because of reduction in cardiovascular disease $(40,41)$, which can be attributed to the beneficial effect of alcohol on plasma lipids levels, hemostatic factors $(2,41)$ and insulin sensitivity (36). Several studies have shown the influence of lifestyle factors on better mortality in moderate drinkers. Moderate alcohol users tend to have higher socioeconomic status, high level of education, increased physical activity and less obesity $(42,43)$. The prevalence of subjects with regular exercise habit was greater in light drinkers in the present study.

Moreover, the present study indicated that in all subjects, the prevalence of obesity, dyslipidemia, IGT, fatty liver, CKD and Mets by the Japanese criteria was decreased among light drinkers compared with among non-drinkers. These results agreed with those of previous reports $(2-9,15-$ $22,36,37,40-45)$. In the non-fatty liver group, because the prevalence of Mets-related diseases was low, no significant relationship between LAC and the prevalence of Mets-related diseases without hypertension was observed. In the fatty liver group, a relationship between LAC and lower prevalence of dyslipidemia, IGT, CKD and Mets by the Japanese criteria was observed. The inverse association between LAC and the prevalence of dyslipidemia, IGT, CKD, and Mets by the Japanese criteria may be explained by an improvement in insulin sensitivity and other metabolic parameters, including improved cytokine profiles and decreased oxidative stress, as has been described in the general population $(8,12,30,44,45)$. NAFLD is considered a phenotype of Mets in the liver (10-12) and in the fatty liver group, the prevalence of each Mets-related disease was actually increased compared with in the non-fatty liver group in this study. Thus, the effect of LAC to suppress Mets-related diseases has been shown more clearly in the fatty liver group.

Nonetheless, numerous studies have shown that alcohol consumption is associated with increased blood pressure. Furthermore, increased alcohol consumption affects endothelial function $(40,46)$. Oda et al (30) reported that light to moderate alcohol consumption impairs endothelial function. Endothelial dysfunction is the initial stage in the pathogenesis of atherosclerosis and plays an important role in the development of atherosclerosis and hypertension. The present study indicated that the prevalence of hypertension is increased in light drinkers compared with in non-drinkers, especially in the non-fatty liver group. While it may suppress fatty liver, LAC may promote hypertension. Increased caloric intake through consuming alcoholic beverages and elevated salt intake associated with drinking may also be involved in alcohol-related hypertension (47). Taking into consideration that liver dysfunction is the most common abnormal finding associated with Mets in a regular health check-up (31), hypertension could occur in Mets-related diseases first. Moreover, in the fatty liver group, no significant relationship between LAC and hypertension was found. VanWagner et al (48) reported that alcohol use may not reduce the risk of cardiovascular disease in patients with NAFLD. A previous study also demonstrated that alcohol use is not associated with a significant difference in markers 
Table III. Comparison of the prevalence of Mets-associated diseases and risk factors between non-drinkers and light drinkers.

A, Prevalence of Mets-associated diseases and risk factors in the non-fatty liver group

\begin{tabular}{lccr}
\hline Characteristic & Non-drinker $(\mathrm{n}=236)$ & Light drinker $(\mathrm{n}=393)$ & P-value \\
\hline Age $($ years $)$ & $56(28-83)$ & $56(24-78)$ & 0.610 \\
BMI $\left(\mathrm{kg} / \mathrm{m}^{2}\right)$ & $21.8(15.2-31.4)$ & $22.1(16.1-33.1)$ & 0.060 \\
Obesity & $28(11.8)$ & $53(13.4)$ & 0.557 \\
Hypertension & $63(26.6)$ & $139(35.3)$ & 0.024 \\
Dyslipidemia & $106(44.9)$ & $148(37.6)$ & 0.073 \\
IGT & $27(11.4)$ & $53(13.4)$ & 0.456 \\
Hyperuricemia & $31(13.1)$ & $61(15.5)$ & 0.413 \\
CKD & $38(16.1)$ & $49(12.4)$ & 0.202 \\
Mets by Japanese criteria & $25(20.5)$ & $45(11.4)$ & 0.741 \\
Regular exercises & $66(27.9)$ & $128(32.5)$ & 0.336 \\
Current smoking & $58(24.5)$ & $71(18.0)$ & 0.050 \\
\hline
\end{tabular}

B, Prevalence of Mets-associated diseases and risk factors in the fatty liver group

\begin{tabular}{lccr}
\hline Characteristic & Non-drinker $(\mathrm{n}=269)$ & Light drinker $(\mathrm{n}=292)$ & P-value \\
\hline Age $($ years $)$ & $56(30-75)$ & $56(31-76)$ & 0.479 \\
BMI $\left(\mathrm{kg} / \mathrm{m}^{2}\right)$ & $25.2(19.3-52.9)$ & $24.8(18.6-41.4)$ & 0.133 \\
Obesity & $146(54.2)$ & $140(47.9)$ & 0.134 \\
Hypertension & $137(50.9)$ & $158(54.1)$ & 0.451 \\
Dyslipidemia & $189(70.2)$ & $179(61.3)$ & 0.026 \\
IGT & $92(34.2)$ & $64(21.9)$ & 0.001 \\
Hyperuricemia & $75(27.8)$ & $87(29.2)$ & 0.617 \\
CKD & $53(19.7)$ & $40(13.6)$ & 0.057 \\
Mets by Japanese criteria & $120(44.6)$ & $98(33.5)$ & 0.007 \\
Regular exercises & $43(15.9)$ & $64(21.9)$ & 0.074 \\
Current smoking & $41(15.2)$ & $53(18.1)$ & 0.357 \\
\hline
\end{tabular}

Results are presented as $\mathrm{n}(\%)$ for qualitative data or as median (range) for quantitative data. Light drinker, $0-19 \mathrm{~g}$ alcohol/day. BMI, body mass index; CKD, chronic kidney disease; IGT, impaired glucose tolerance; Mets, metabolic syndrome.

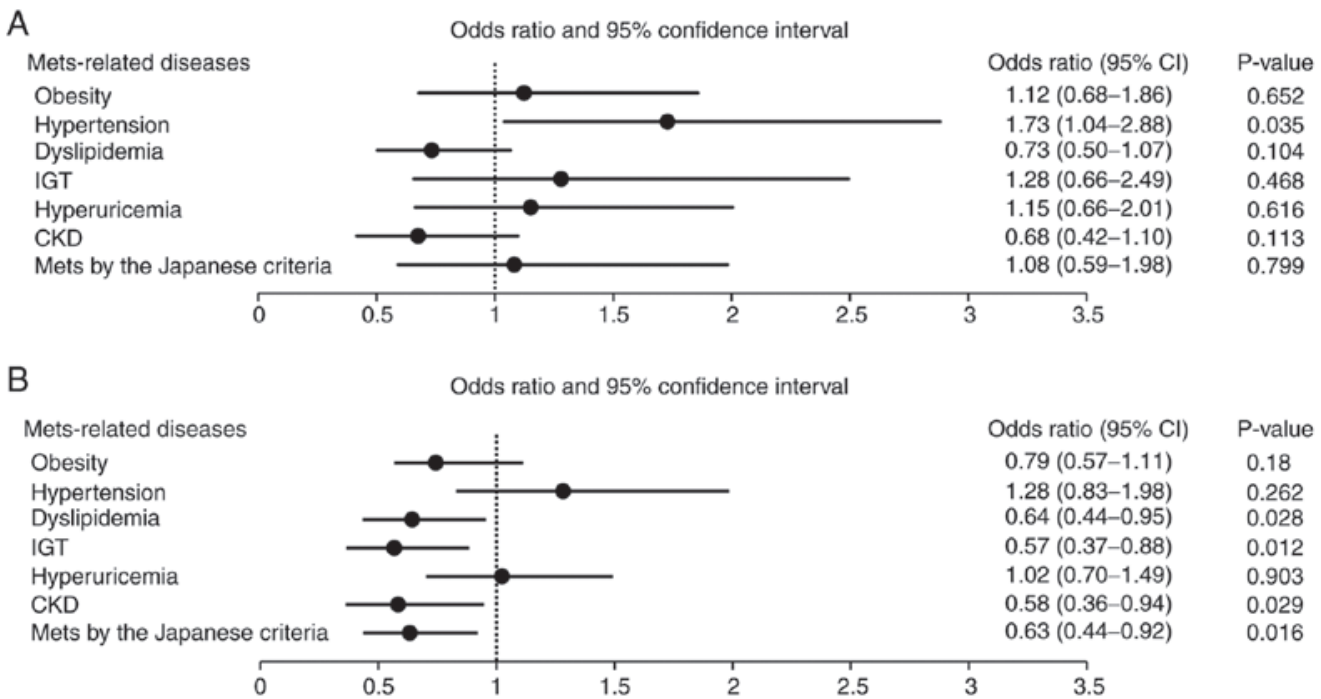

Figure 2. Odds ratio for each Mets-related disease in light drinkers and non-drinkers (adjusted for age, regular exercise, smoking, and usage of drugs that potentially affect Mets-related diseases). (A) Non-fatty liver group. (B) Fatty liver group. CKD, chronic kidney disease; IGT, impaired glucose tolerance; Mets, metabolic syndrome; CI confidence interval. 
of subclinical atherosclerosis, such as coronary artery calcium, which is a well-established risk marker for future cardiovascular events (49).

This study has some limitations. Eating habits, which may have an influence on Mets-related diseases and the types of beverages consumed were not evaluated. Selection bias was also possible. Most of the participants were healthy and willing to undergo medical check-up. Further studies are needed to address these limitations.

In conclusion, the present study found that the effect of LAC was different between individuals with and those without fatty liver. In the non-fatty liver group, LAC may increase the risk of hypertension, whereas in the fatty liver group, LAC may decrease the prevalence of dyslipidemia, IGT, CKD and Mets by the Japanese criteria. The effect of LAC to suppress Mets-related diseases has been shown more clearly in the fatty liver group, because of the higher prevalence of each Mets-related disease. On the other hand, it may suppress fatty liver and LAC may promote hypertension.

\section{Acknowledgements}

The authors thank all the members of the Department of Gastroenterology and Hepatology, Fukuchiyama City Hospital. The authors would also like to thank Noriko for assistance with data collection.

\section{Funding}

No funding was received.

\section{Availability of data and materials}

The datasets of the present study are available from the corresponding author on reasonable request.

\section{Authors' contributions}

The study was conducted and designed by TH. TH, NI, YIn, TT, TO, TK and KK collected and interpreted clinical data. The results were analyzed and interpreted by TH, YS and YIt. TH wrote the first draft of the manuscript and YS and YIt contributed to the writing of the manuscript. All authors have read and approved the final version of the manuscript.

\section{Ethics approval and consent to participate}

This study was conducted in accordance with the Declaration of Helsinki and approved by the institutional review board of Fukuchiyama City Hospital (Fukuchiyama City, Japan). All patients provided written informed consent prior to participation.

\section{Patient consent for publication}

Not applicable.

\section{Competing interests}

All authors declare that they have no competing interests.

\section{References}

1. Deepa M, Farooq S, Datta M, Deepa R and Mohan V: Prevalence of metabolic syndrome using WHO, ATPIII and IDF definitions in Asian Indians: The chennai urban rural epidemiology study (CURES-34). Diabetes Metab Res Rev 23: 127-134, 2007.

2. Gaziano JM, Buring JE, Breslow JL, Goldhaber SZ, Rosner B, VanDenburgh M, Willett W and Hennekens $\mathrm{CH}$ : Moderate alcohol intake, increased levels of high-density lipoprotein and its subfractions, and decreased risk of myocardial infarction. N Engl J Med 329: 1829-1834, 1993.

3. Conigrave KM, Hu BF, Camargo CA Jr, Stampfer MJ, Willett WC and Rimm EB: A prospective study of drinking patterns in relation to risk of type 2 diabetes among men. Diabetes 50: 2390-2395, 2001

4. Mukamal KJ, Conigrave KM, Mittleman MA, Camargo CA Jr, Stampfer MJ, Willett WC and Rimm EB: Roles of drinking pattern and type of alcohol consumed in coronary heart disease in men. N Engl J Med 348: 109-118, 2003.

5. Tolstrup J, Jensen MK, Tjonnald A, Overvad K, Mukamal KJ and Grønbaek M: Prospective study of alcohol drinking patterns and coronary heart diseases in women and men. BMJ 332: 1244-1248, 2006.

6. Gaziano JM, Gaziano TA, Glynn RJ, Sesso HD, Ajani UA, Stampfer MJ, Manson JE, Hennekens $\mathrm{CH}$ and Buring JE: Light-to-moderate alcohol consumption and mortality in the Physicians' Health Study enrollment cohort. J Am Coll Cardiol 35: 96-105, 2000.

7. Freiberg MS, Cabral HJ, Heeren TC, Vasan RS and Curtis Ellison R; Third National Health and Nutrition Examination Survey: Alcohol consumption and the prevalence of the metabolic syndrome in the US: A cross-sectional analysis of data from the Third National Health And Nutrition Examination Survey. Diabetes Care 27: 2954-2959, 2004.

8. Thun MJ, Peto R, Lopez AD, Monaco JH, Henley SJ, Heath CW Jr and Doll R: Alcohol consumption and mortality among middle-aged and elderly U.S. adults. N Engl J Med 337: 1705-1714, 1997.

9. Wannamethee SG, Camargo CA Jr, Manson JE, Willett WC and Rimm EB: Alcohol drinking patterns and risk of type 2 diabetes mellitus among younger women. Arch Intern Med 163: 1329-1336, 2003.

10. Neuschwander-Tetri BA: Nonalcoholic steatohepatitis and the metabolic syndrome. Am J Med Sci 330: 326-335, 2005.

11. Marchesini G, Brizi M, Bianchi G, Tomassetti S, Bugianesi E, Lenzi M, McCullough AJ, Natale S, Forlani G and Melchionda N: Nonalcoholic fatty liver disease: A feature of the metabolic syndrome. Diabetes 50: 1844-1850, 2001.

12. Eckel RH, Grundy SM and Zimmet PZ: The metabolic syndrome. Lancet 365: 1415-1428, 2005.

13. Eguchi Y, Hyogo H, Ono M, Mizuta T, Ono N, Fujimoto K, Chayama K and Saibara T; JSG-NAFLD: Prevalence and associated metabolic factors of nonalcoholic fatty liver disease in the general population from 2009 to 2010 in Japan: A multicenter large retrospective study. J Gastroenterol 47: 586-595, 2012.

14. Nishioji K, Sumida Y, Kamaguchi M, Mochizuki N, Kobayashi M, Nishimura T, Yamaguchi K and Itoh Y: Prevalence of and risk factors for non-alcoholic fatty liver diseases in a non-obese Japanese population, 2011-2012. J Gastroenterol 50: 95-108, 2015.

15. Dunn W, Xu R and Schwimmer JB: Modest wine drinking and decreased prevalence of suspected nonalcoholic fatty liver disease. Hepatology 47: 1947-1954, 2008.

16. Gunji T, Matsuhashi N, Sato H, Fujibayashi K, Okumura M, Sasabe $\mathrm{N}$ and Urabe A: Light and moderate alcohol consumption significantly reduces the prevalence of fatty liver in the Japanese male population. Am J Gastroenterol 104: 2189-2195, 2009.

17. Moriya A, Iwasaki Y, Ohguchi S, Kayashima E, Mitsumune T, Taniguchi H, Ikeda F, Shiratori Y and Yamamoto K: Alcohol consumption appears to protect against non-alcoholic fatty liver disease. Aliment Pharmacol Ther 33: 378-388, 2011.

18. Hamaguchi M, Kojima T, Ohbora A, Takeda N, Fukui M and Kato T: Protective effect of alcohol consumption for fatty liver but not metabolic syndrome. World J Gastroenterol 18: 156-167, 2012.

19. Sogabe M, Okahisa T, Taniguchi T, Tomonari T, Tanaka T, Tanaka H, Nakasono $\mathrm{M}$ and Takayama T: Light alcohol consumption plays a protective role against non-alcoholic fatty liver disease in Japanese men with metabolic syndrome. Liver Int 35: 1707-1714, 2015. 
20. Kang HT, Kim JK, Shim JY, Lee HR, Linton JA and Lee YJ: Low grade inflammation, metabolic syndrome and the risk of chronic kidney disease: The 2005 Korean national health and nutrition examination survey. J Korean Med Sci 27: 630-635, 2012.

21. Yamagata K, Ishida K, Sairenchi T, Takahashi H, Ohba S, Shiigai T, Narita M and Koyama A: Risk factors for chronic kidney disease in a community-based population: A 10-year follow-up study. Kidney Int 71: 159-166, 2007.

22. Shankar A, Klein R and Klein BE: The association among smoking, heavy drinking, and chronic kidney disease. Am J Epidemiol 164: 263-271, 2006.

23. Jalal DI, Chonchol M, Chen W and Targher G: Uric acid as a target of therapy in CKD. Am J Kidney Dis 61: 134-146, 2013.

24. Kodama S, Saito K, Yachi Y, Asumi M, Sugawara A, Totsuka K, Saito A and Sone H: Association between serum uric acid and development of type 2 diabetes. Diabetes Care 32: 1737-1742, 2009.

25. Feig DI, Kang DH and Johnson RJ: Uric acid and cardiovascular risk. N Engl J Med 359: 1811-1821, 2008.

26. Nakamura K, Sakurai M, Miura K, Morikawa Y, Yoshita K, Ishizaki M, Kido T, Naruse Y, Suwazono Y and Nakagawa H: Alcohol intake and the risk of hyperuricemia: A 6-year prospective study in Japanese men. Nutr Metab Cardiovasc Dis 22: 989-996, 2012.

27. Li Z, Guo X, Liu Y, Chang Y, Sun Y, Zhu G and Abraham MR: The relation of moderate alcohol consumption to hyperuricemia in a rural general population. Int J Environ Res Public Health 13 E732, 2016 .

28. Nakamura K, Okamura T, Hayakawa T, Hozawa A, Kadowaki T, Murakami Y, Kita Y, Okayama A and Ueshima H; NIPPON DATA90 Research Group: The proportion of individuals with alcohol-induced hypertension among total hypertensives in a general Japanese population: NIPPON DATA90. Hypertens Res 30: 663-668, 2007.

29. Okubo Y, Sairenchi T, Irie F, Yamagishi K, Iso H, Watanabe H, Muto T, Tanaka K and Ota H: Association of alcohol consumption with incident hypertension among middle-aged and older Japanese population: The Ibaraki Prefectural Hearth Study (IPHS). Hypertension 63: 41-47, 2014.

30. Oda N, Kajikawa M, Maruhashi T, Iwamoto Y, Kishimoto S, Matsui S, Hidaka T, Kihara Y, Chayama K, Goto C, et al: Endothelial function is impaired in relation to alcohol intake even in the case of light alcohol consumption in Asian men: Flow-mediated Dilation Japan (FMD-J) Study. Int J Cardiol 230: 523-528, 2017.

31. Research Committee for the Mega Database of Japan Society of Ningen Dock, May 2019: Nationwide data analysis of the Ningen Dock in 2016 (Part 1) (In Japanese). https://www.ningen-dock. jp/wp/wp-content/uploads/2013/09/2016dockdata-No1.pdf. Accessed May 31, 2019.

32. Matsuzawa Y: Metabolic syndrome-definition and diagnostic criteria in Japan. J Atheroscler Thromb 12: 301, 2005.

33. Hamaguchi M, Kojima T, Itoh Y, Harano Y, Fujii K, Nakajima T, Kato T, Takeda N, Okuda J, Ida K, et al: The severity of ultrasonographic findings in nonalcoholic fatty liver disease reflects the metabolic syndrome and visceral fat accumulation. Am J Gastroenterol 102: 2708-2715, 2007

34. Examination Committee of Criteria for 'Obesity Disease' in Japan; Japan Society for the Study of Obesity: New criteria for 'obesity disease' in Japan. Circ J 66: 987-992, 2002.

35. Levey AS, Coresh J, Balk E, Kausz AT, Levin A, Steffes MW, Hogg RJ, Perrone RD, Lau J and Eknoyan G; National Kidney Foundation: National Kidney Foundation practice guidelines for chronic kidney disease: Evaluation, classification, and stratification. Ann Intern Med 139: 137-147, 2003.
36. Kiechl S, Willeit J, Poewe W, Egger G, Oberhollenzer F, Muggeo $M$ and Bonora E: Insulin sensitivity and regular alcohol consumption: Large, prospective, cross sectional population study (Bruneck study). BMJ 313: 1040-1044, 1996.

37. Sierksma A, Patel H, Ouchi N, Kihara S, Funahashi T, Heine RJ, Grobbee DE, Kluft C and Hendriks HF: Effect of moderate alcohol consumption on adiponectin, tumor necrosis factor-alpha, and insulin sensitivity. Diabetes Care 27: 184-189, 2004.

38. Pischon T, Girman CJ, Rifai N, Hotamisligil GS and Rimm EB: Association between dietary factors and plasma adiponectin concentration in men. Am J Clin Nutr 81: 780-786, 2005.

39. You M, Considine RV, Leone TC, Kelly DP and Crabb DW: Role of adiponectin in the protective action of dietary saturated fat against alcoholic fatty liver in mice. Hepatology 42: 568-577, 2005.

40. Rimm EB, Giovannucci EL, Willett WC, Colditz GA, Ascherio A, Rosner B and Stampfer MJ: Prospective study of alcohol consumption and risk of coronary disease in men. Lancet 338: 464-468, 1991.

41. Rimm EB, Williams P, Fosher K, Criqui M and Stampfer MJ: Moderate alcohol intake and lower risk of coronary heart disease: Meta-analysis of effects on lipids and haemostatic factors. BMJ 319: 1523-1528, 1999.

42. Mukamal KJ, Ding EL and Djoussé L: Alcohol consumption, physical activity, and chronic disease risk factors: A population-based cross-sectional survey. BMC Public Health 6: 118, 2006.

43. Fillmore KM, Golding JM, Graves KL, Kniep S, Leino EV, Romelsjö A, Shoemaker C, Ager CR, Allebeck P and Ferrer HP: Alcohol consumption and mortality. I. Characteristics of drinking groups. Addiction 93: 183-203, 1998

44. Goude D, Fagerberg B and Hulthe J; AIR Study Group: Alcohol consumption, the metabolic syndrome and insulin resistance in 58-year-old clinically healthy men (AIR study). Clin Sci (Lond) 102: 345-352, 2002.

45. Yoon YS, Oh SW, Baik HW, Park HS and Kim WY: Alcohol consumption and the metabolic syndrome in Korean adults: The 1998 Korean National Health and Nutrition Examination Survey. Am J Clin Nutr 80: 217-224, 2004.

46. Rehm J, Mathers C, Popova S, Thavorncharoensap M, Teerawattananon Y and Patra J: Global burden of disease and injury and economic cost attribute to alcohol use and alcohol-use disorders. Lancet 373: 2223-2233, 2009.

47. Kawano Y: Physio-pathological effects of alcohol on the cardiovascular system: Its role in hypertension and cardiovascular disease. Hypertens Res 33: 181-191, 2010.

48. VanWagner LB, Ning H, Allen NB, Ajmera V, Lewis CE, Carr JJ, Lloyd-Jones DM, Terrault NA and Siddique J: Alcohol use and cardiovascular disease risk in patients with nonalcoholic fatty liver disease. Gastroenterology 153: 1260-1272, 2017.

49. Yeboah J, McClelland RL, Polonsky TS, Burke GL, Sibley CT, O'Leary D, Carr JJ, Goff DC, Greenland P and Herrington DM: Comparison of novel risk markers for improvement in cardiovascular risk assessment in intermediate-risk individuals. JAMA 308: 788-795, 2012.

This work is licensed under a Creative Commons Attribution-NonCommercial-NoDerivatives 4.0 International (CC BY-NC-ND 4.0) License. 